\title{
Climate Change Disclosures in the Annual Reports: Evidence from Bangladesh
}

\author{
Pappu Kumar Dey \\ Assistant Professor \\ Department of Accounting \& Information Systems \\ Jahangirnagar University, Savar, Dhaka-1342, Bangladesh \\ E-mail: pappudey@juniv.edu \\ Mohammad Nakib \\ Postgraduate student \\ Department of Accounting \& Information Systems \\ Jahangirnagar University, Savar, Dhaka-1342, Bangladesh \\ Probal Dutta \\ Associate Professor \\ Department of Accounting \& Information Systems \\ Jahangirnagar University, Savar, Dhaka-1342, Bangladesh
}

$\begin{array}{ll}\text { Received: August 22, } 2017 & \text { Accepted: Sep. 28, 2017 } \quad \text { Published: December 1, } 2017 \\ \text { doi:10.5296/ajfa.v9i2.11736 } & \text { URL: https://doi.org/10.5296/ajfa.v9i2.11736 }\end{array}$

Abstract
This study examines the nature and extent of climate change disclosures in the corporate
annual reports of the listed companies in Dhaka Stock Exchange, Bangladesh. For this
purpose, annual reports related to the year 2014 of the sample 88 listed companies have been
scrutinized. In regard to this study, content analysis approach has been conducted considering
thirteen different disclosure issues regarding climate change. Our analysis provides the
comprehension of below average climate change disclosure practices by the Bangladeshi 
companies, though 58 percent companies have reported at least one issue on climate change and global warming. 'Energy saving \& efficiency' and 'water management \& pollution' are mostly reported issues that are industry specific requirements in some case. From the viewpoint of industry, Banking industry and Cement industry have started to report some issues related to the climate change, where 4 industries out of selected 17 industries have not provided any climate change disclosure. Disseminating climate change disclosure within 10 sentences by most of the reported companies manifests the desideratum of in-depth disclosure practices.

Keywords: Climate change, climate change disclosures, annual reports, content analysis, Dhaka Stock Exchange, Bangladesh 


\section{Introduction}

Climate change has been a burning issue as its drastic impacts are being apprehended and its dreadful effects are appearing and intensifying day by day. Climate change is not just an environmental issue; it directly affects many social and economic phenomena such as poverty, health and economic development in a wider context (ACCA, 2009). According to Global Climate Risk Index 2016, Bangladesh has been the sixth most affected countries with Climate Risk Index (CRI) score of 22.67 from 1995 to 2014. Though developed countries in Asia, Europe and North America are held primarily responsible for this climate change, developing countries can no longer evade their responsibilities of working towards reducing the severe effects of climate change. Having the recognition of lower-middle income country (World Bank, 2015b), the business organizations of Bangladesh are more being sought to work in reducing the impacts of climate change.

Business organizations are seen as one of the leading contributors to climate change and needed to perform works which are environmentally sustainable. While the world is facing the substantial threat of climate change, the business can act in response by ensuing more efficient product and production techniques, figuring a way out to attain the goals sustainably (CECP, 2010). Abiding by the social contract, the business ensures that it enhances the welfare of the society as a whole. Otherwise, it will have to undergo reproach of the society (Donaldson, 1982). At present, changing social contract persuades business organizations to focus on their activities to reduce environmental hazards and make them more accountable towards their contribution to the climate change.

Over the last few decades, many companies across the world have voluntarily disclosed qualitative information on social \& environmental related issues. Legitimacy theory asserts that "organizations continually seek to ensure that they are perceived as operating within the bounds and norms of their respective societies-that is, they attempt to ensure that their activities are perceived by outside parties as being legitimate" (Deegan, 2009). It depends on the notion of a social contract that is an implied contact between the firm and the society in which a firm operates. Like an individual in the society, organizations have to comply with the rules, regulations, norms, values and ethics of the society. In addition, the activities of the businesses should not harm the society in any manner. Therefore, to be 'legitimate' in the society, business organizations should always go for some social activities to meet the expectations of society. In other word, corporate activities and performance disclosures are used to legitimize the ongoing operation of business. Even when legitimacy is threatened, imparting disclosures are one strategy to restore legitimacy. Corporate social activities and disclosures also help business manage impression. Corporate environmental and climate change reporting can be considered as a strategic approach of managing impression and maintaining legitimacy to the society.

The objective of this research is to conduct an analysis of the climate change disclosure practices in the corporate annual reports of the companies, listed in Dhaka Stock Exchange (DSE) of Bangladesh. 
The paper proceeds as follows. The next section briefly discusses climate change and Bangladesh. Section three reviews the literature on climate change and its disclosures. Section four explains the methodology of the study. Findings and analysis are presented in section five. The final section provides conclusion.

\section{Climate change and Bangladesh}

Climate change refers to a long-term change in average weather conditions. Climate change may be due to natural courses or external forces or persistent anthropogenic changes in the composition of the atmosphere or in land use. According to the United Nations (1992), "Climate change is a change of climate which is attributed directly or indirectly to human activity that alters the composition of the global atmosphere and which is in addition to natural climate variability observed over comparable time periods." From the definition, United Nations makes a clear distinction between 'climate change' attributable to human activities and 'climate variability (change)' attributable to natural causes.

Bangladesh is one of the most climate vulnerable countries in the world and will become more so as a result of climate change (MoEF, 2009). Climate change is imposing a deal of great threats to the residents, ecological balances and living environments of Bangladesh, a developing country which has just touched the recognition of lower-middle income (World Bank, 2015b). Millions of people are suffering because of climate change and each year handsome numbers of people are being added to the list. Because of climate change and global warming, sea level rise in the coming decades will create over 25 million climate refugees (DoE, 2007). This is twice the entire population of the Netherlands (DoE, 2007). According to Ministry of Planning (2016), about 13\% of the households and $12.64 \%$ of the population live in the disaster prone area and are being affected by climate change. In 2015, Bangladesh Bureau of Statistics reported that Bangladesh suffered a financial loss of $\$ 2.33$ billion because of natural calamities for which climate change is directly responsible (Ministry of Planning, 2016).

During the last century, the temperature has experienced an increase of 2 to 4 degrees and this trend is intensifying gradually. Climate change in Bangladesh is demonstrating its devastative expressions by means of lower crop yields, higher sea levels, frequent floods, more intense cyclones and tornadoes, extreme rainfall, droughts, salinity, extreme fog and cold waves etc. (World Bank, 2014). Floods are frequently visiting in Bangladesh. According to the report of International Federation of Red Cross and Red Crescent Societies (2014), by the flood of August of 2014, around 2.8 million people were affected. According to Inter-governmental Panel on Climate Change (IPCC) (2007), the sea level may rise by $31 \mathrm{~cm}$ to $71 \mathrm{~cm}$ by 2100 . In case of Bangladesh, the sea level may rise even by larger figure. IPCC forecasts that the sea level of Bay of Bengal can rise by $0.2 \mathrm{~m}$ to $1 \mathrm{~m}$ by 2100 . In 2008, Bangladesh Water Development Board found that at Hiron Point of Sundarban, the sea level rose by $5.6 \mathrm{~mm}$ (The Daily Star, 2013). Southeast coastal areas will be severely affected by increasing river salinity which will lead to shortages of drinking water, irrigation and impose a major threat to the aquatic systems. Cropping yield in the coastal area is under great 
intimidation for the soil salinity and it is anticipated that yield of rice will decline $15.6 \%$ by 2050 (World Bank, 2015a).

Industries greatly rely on the burning fossil fuels for production. Business sector is one of the main responsible parties for global warming and climate change. So since last decade, activities of the business are getting monitored by several stakeholders like the government, social parties, media and others. Especially after the agreement naming the Kyoto Protocol in 1997 signed by almost 175 countries, business organizations are constantly facing pressure from the part of different stakeholders (Ahmad \& Hossain, 2015). The Bangladesh Climate Change Strategy and Action Plan (MoEF, 2009) notes the involvement of the private and business sector in meeting the challenges of climate change. In this context, the extent and nature of actual responses in relation to climate changes of business firms can be examined.

\section{Literature Review}

Climate change is an issue that calls for a corporate response as climate change significantly impacts business operations. One of the main future risks to business and society is the consequences of climate change (ACCA, 2007). One possible response is to account for and report on these issues (Hopwood, 2009).

In the social and environmental accounting literature, corporate disclosures on social and environmental issue were studied over the last decade. Of late, climate change and global warming issue has unlocked newer avenues for social and environmental accounting researchers (Ahmad \& Hossain, 2015). Given the emergent impact of climate change, more specific accounting and reporting standards have been developed e.g. Climate Disclosure Standards Board (CDSB)'s Climate Change Reporting Framework (CCRF), Greenhouse Gas (GHG) Protocol Corporate accounting \& Reporting Standard, GHG Protocol Corporate Value Chain Accounting \& Reporting Standard, GHG Protocol Product Life Cycle Accounting \& Reporting Standard. These standards mainly aim at eliciting information to stakeholders on how climate change affects the strategy, performance and prospect of organization through disclosure of GHG emissions, climate change mitigation, adaptation measures etc.

Climate change disclosure by the corporation is still an under-researched area (Ahmad \& Hossain, 2015). Ahmad \& Hossain (2015) have found four kinds of studies on climate change and environmental issues. They are (a) empirical studies on disclosure, (b) conceptual/ theoretical/ normative studies, (c) studies specially conducted for practitioners to provide with guidelines and (d) literature reviews. The empirical studies include mainly two types of research. Firstly, the opinion surveys that generally include responses of the respondents. Secondly, the content analysis that is found to be the most commonly used research techniques in the field of social and environmental accounting research (Guthrie \& Abeysekera, 2006). Most of the studies (e.g. Freedman and Jaggi, 2010; Belal et al., 2010; Rankin, Windsor \& Wahyuni, 2011; Pellegrino \& Lodhia, 2012; Luo, Tang \& Lan, 2013, Ahmad \& Hossain, 2015) followed content analysis of annual reports and websites. Hence in this research paper, content analysis research technique has also been used. 


\section{Macrothink}

Nurunnabi (2015) found that the level of disclosure on climate change by the Bangladeshi companies is very low i.e. only an average of $2.23 \%$. The relationship between size of the company and the level of climate change disclosure is positively associated (Nurunnabi, 2015; Luo \& Tang, 2014; Meng et al., 2014). Large companies are disclosing more climate change related information in their annual reports in order to legitimize their position in the market (Meng et al., 2014; Patten, 2002). Nurunnabi (2015) suggested that lack of regulation and a culture of low social accountability among the companies contribute to a low level of disclosure.

Belal et al. (2010) studied on developing country i.e. Bangladesh. They found that the level of environmental and climate change disclosures in annual report and website is very low in Bangladesh. Only few companies made disclosures in the specific areas of climate change but interestingly they popularly disclose adaptation measures. The nature of disclosures is mostly positive and descriptive. Luo, Tang \& Lan (2013) studied on both developed and developing countries in order to make a comparison between their carbon disclosure patterns. Most of the researchers on the climate change issues, especially on carbon accounting, are based on developed countries (Stechemesser \& Guenther, 2012). Developing or less developed countries, as well as the Asian countries got less importance from the researchers (Ahmad \& Hossain, 2015). Therefore, Ahmad \& Hossain (2015) studied on developing country, i.e. Malaysia. They found that in spite of being voluntary of disclosing climate change and global warming issues in Malaysia, some companies are disclosing some issues related to climate change and global warming and it is still at its introductory stage. The nature and extent of the language of disclosure were mostly ignored in the previous studies. Notably, Belal et al. (2010) selected top 100 companies listed in DSE on the basis of their market capitalization. But in this research, 88 companies listed in DSE of Bangladesh were selected using systematic random sampling. This sample is more representable as companies from all industries have been selected in the sample.

\section{Methodology of the Study}

This study is empirical in nature based on secondary data source. Annual report is the most useful written form of communication for corporate reporting. Hence, annual reports were chosen as the main source of secondary data. The study collected data on climate change disclosures from the annual reports of listed companies in Bangladesh. All industrial sectors were considered to select sample companies. 88 companies listed in Dhaka Stock Exchange (DSE) of Bangladesh have been selected using systematic random sampling. The data of this study covered the annual reports of 88 companies of the year 2014 . 
Table 1. Sample description

\begin{tabular}{|c|c|c|}
\hline Industry & $\begin{array}{l}\text { No of listed companies } \\
\qquad(\mathrm{N}=248)\end{array}$ & $\begin{array}{l}\text { No of sample companies } \\
(\mathrm{n}=88)\end{array}$ \\
\hline Bank & 30 & 10 \\
\hline Cement & 7 & 3 \\
\hline Ceramics & 5 & 2 \\
\hline Engineering & 26 & 9 \\
\hline Financial Institutions & 23 & 8 \\
\hline Food \& Allied & 17 & 6 \\
\hline Fuel \& Power & 15 & 5 \\
\hline Insurance & 46 & 16 \\
\hline IT & 6 & 2 \\
\hline Jute & 3 & 1 \\
\hline Paper \& Printing & 1 & 1 \\
\hline Pharmaceuticals \& Chemicals & 24 & 8 \\
\hline Services \& Real Estate & 4 & 2 \\
\hline Tannery & 5 & 2 \\
\hline Telecommunication & 2 & 1 \\
\hline Textile & 31 & 11 \\
\hline Travel \& Leisure & 3 & 1 \\
\hline Total & 248 & 88 \\
\hline
\end{tabular}

The content analysis technique was conducted to analyze the annual reports. Content analysis is found to be the most commonly used method of research in social and environmental accounting (Guthrie \& Abeysekera, 2006). Data were analyzed through using the content analysis outline of item (Climate change disclosures index), nature and extent. A disclosure index is generally prepared to examine whether the sampled companies engage in disclosure practices of particular information in annual reports (Marston \& Shrives, 1991). Many researchers have developed different disclosure indices to measure the level of disclosure practices of selected companies (Ahmad \& Hossain, 2015; Belal et al., 2010). With the help of prior studies, the present study constructed a climate change disclosure index that comprises 13 issues/items on climate change.

Detailed descriptions of the particular items of the index are given in Table 2 below: 
Table 2. Climate change disclosures index

Disclosure issue

Energy saving \& efficiency

Renewable energy \& solar panel

GHG (or carbon) emission

Tree plantation

Air pollution

Water management \& pollution

Recycling \& waste management

Preserving biodiversity

Adaption measures

Climate change policy statement

Product impacts on climate change

Reference to standard/protocol

Other climate change issues
Studies using the same items or new items added

by the researchers

(Ahmad \& Hossain, 2015)

Added by the researchers

(Ahmad \& Hossain, 2015); (Belal, et al., 2010)

(Ahmad \& Hossain, 2015)

(Ahmad \& Hossain, 2015); (Belal, et al., 2010)

Added by the researchers

Added by the researchers

(Ahmad \& Hossain, 2015)

(Belal et al., 2010)

(Belal et al., 2010); (Ahmad \& Hossain, 2015)

(Belal et al., 2010)

(Belal et al., 2010); (Ahmad \& Hossain, 2015)

(Belal et al., 2010)

\section{Findings and Analysis}

This section deals with the analysis of nature and extent of the climate change disclosures by the sample Bangladeshi companies and figures out the findings linked with current practices. The following table provides the enacting comprehension about the climate change disclosure practices by the Bangladeshi companies.

Table 3. Overall climate change disclosures by the Bangladeshi companies

Description

Percentage

$(\%)$

Total percentage of companies with disclosures in at least one item or 58 category

Total percentage of companies with no disclosures 42

Total 100

Table 3 exhibits that $58 \%$ of the sample Bangladeshi companies disclosed climate change disclosures in at least one item or category in their annual reports. $42 \%$ of the sample companies didn't disclose any issue on climate change. This table construes that the climate change disclosure practices by the Bangladeshi companies is medium. 
Table 4. Main themes or issues of climate change disclosures by the Bangladeshi companies

\begin{tabular}{lccc}
\hline Issue/ Theme & $\begin{array}{c}\text { No of companies } \\
\text { disclosing the } \\
\text { issue }\end{array}$ & $\begin{array}{c}\text { \% of the total } \\
\text { number of disclosing } \\
\text { companies (51) }\end{array}$ & $\begin{array}{c}\text { \% of the } \\
\text { total sample } \\
\text { (n=88) }\end{array}$ \\
\hline Energy saving \& efficiency & 26 & 50.98 & 29.55 \\
Renewable energy \& solar panel & 8 & 15.69 & 9.09 \\
GHG (or carbon) emission & 14 & 27.45 & 15.91 \\
Tree plantation & 14 & 27.45 & 15.91 \\
Air pollution & 11 & 21.57 & 12.50 \\
Water management \& pollution & 30 & 58.82 & 34.09 \\
Recycling \& waste management & 9 & 17.65 & 10.23 \\
Preserving biodiversity & 10 & 19.60 & 11.36 \\
Adaption measures & 19 & 37.25 & 21.59 \\
Climate change policy statement & 13 & 25.49 & 14.77 \\
Product impacts on climate change & 13 & 25.49 & 14.77 \\
Reference to standard/protocol & 15 & 29.41 & 17.05 \\
Other climate change issues & 12 & 23.53 & 13.64 \\
\hline
\end{tabular}

Table 4 displays category or item-wise analysis of climate change disclosure practices. Energy saving and efficiency is one of the most reported issues or themes by the sample companies. 26 sample companies (29.55\%) reported energy saving and efficiency related disclosures. These companies are $50.98 \%$ of the total number of disclosing companies. BATBC published in its annual reports, "We have installed energy efficient rated motors for compressors. We have installed an $11 \mathrm{kw}$ capacity solar panel to run office lights and AC's. We have installed wind turbines and exhaust fan outlet to gain electricity. All these initiatives have contributed in reducing energy consumption and saving a lot of money." (British American Tobacco Bangladesh Company Limited, 2015, p. 88). Besides, Renewable energy and solar panel have been observed to be reported in the annual reports. 8 companies out of our 88 sample companies, which are $15.69 \%$ of the disclosing companies and $9.09 \%$ of the sample companies, have reported renewable energy and solar panel in their annual reports.

Only $15.91 \%$ of the companies (14 sample companies) reported GHG or carbon emission related disclosures in their annual reports. An example of disclosing GHG or carbon emission disclosure is that BRAC Bank Ltd stated "BIVL aims to provide services in Climate change, Agriculture, Water, Health, Energy and Financial sector by Creating Jobs, Reducing GHG emission and utilizing suppliers living in the base of the financial pyramid." (Brac Bank Ltd, 2015, p. 127)

Tree plantation and air pollution got attention by 14 and 11 companies respectively. In case of water management and pollution, 34.09\% of companies (30 sample companies) disclosed this issue. This is the most reported category or item disclosed by the sample companies in their annual reports, which are $58.82 \%$ of the total disclosing companies. Most of the 
companies who reported water management and pollution related disclosures mentioned about the establishment of Effluent Treatment Plant (ETP) in order to reduce water pollution. The Dacca Dyeing and Manufacturing Co. Ltd declared in its annual report, "The company has completed installation of a biological Effluent Treatment Plant (ETP) having $180 \mathrm{~cm}$ capacity per hour with a cost of Tk. 10 crore." (Dacca Dyeing and Manufacturing Co. Ltd, 2015, p. 16)

Recycling and waste management have been reported by 9 of the sample companies $(10.23 \%$ of the sample companies) as they apprehended their responsibilities to reduce their individual contributions to the climate change. National Polymer Industries Ltd. highlighted its initiative by mentioning in its annual report, "We recycle our waste materials and minimize waste of energy. We are very careful making our plant and its surroundings free from contamination". (National Polymer Industries Ltd., 2015, p.10)

Preserving biodiversity issue has been delineated in only $11.36 \%$ of the sample companies' annual reports which is the least reported issue regarding the climate change disclosures. Only the companies from cement, food and allied and fuel and power industries tried to provide disclosures regarding preserving biodiversity to an average extent. Regarding preservation of biodiversity Summit Power Ltd alluded, "Biodiversity entails protecting plant and animal species and ecosystems. This is an essential component of our health, safety and environmental commitments. We address biodiversity conservation during the planning and development of major projects by conducting environmental impact assessments, implementing mitigation and monitoring programs to reduce impacts." (Summit Power Ltd, 2015, p. 77)

About $21.59 \%$ of the total sample companies or in another way $37.25 \%$ of the total disclosing companies disclosed adaptation measures. Other than these, companies reported on Climate change policy statements (14.77\%), product impacts on climate change (14.77\%) and reference to different standards, guidelines and protocol (17.09\%).

Besides, $13.64 \%$ of the sample companies which are $23.53 \%$ of the disclosing companies disclosed other issues related to climate change. Among such issues dust pollution, oil spillage, soil pollution etc. are noteworthy. Premier Cement Ltd delineated, "We are cement manufacturer and dust is an integral part of our production process. Suspended particle and dust can affect the environment and human health severely. Without dust control equipment large dust emission with occur at several stages in the entire production process. As we never compromise on any issue related to environment, therefore our whole production units are equipped with adequate number of dust collectors to the amount of suspended particles in the air far below than the acceptable limit." (Premier Cement Ltd, 2015, p. 40) 


\section{Macrothink \\ Asian Journal of Finance \& Accounting \\ ISSN 1946-052X \\ 2017, Vol. 9, No. 2}

Table 5. Industry/sector-wise climate change disclosures index

\begin{tabular}{lcccc}
\hline Industry/Sector & $\begin{array}{c}\text { No of sample } \\
\text { companies } \\
(\mathrm{n}=88)\end{array}$ & $\begin{array}{c}\text { Maximum } \\
\text { probable score }\end{array}$ & $\begin{array}{c}\text { Actual } \\
\text { score }\end{array}$ & $\begin{array}{c}\% \text { of } \\
\text { disclosures }\end{array}$ \\
\hline Bank & 10 & 130 & 78 & 60.00 \\
Cement & 3 & 39 & 18 & 46.15 \\
Ceramics & 2 & 26 & 1 & 3.85 \\
Engineering & 9 & 117 & 7 & 5.98 \\
Financial Institutions & 8 & 104 & 23 & 22.12 \\
Food \& Allied & 6 & 78 & 16 & 20.51 \\
Fuel \& Power & 5 & 65 & 18 & 27.69 \\
Insurance & 16 & 208 & 14 & 6.73 \\
IT & 2 & 26 & 0 & Nil \\
Jute & 1 & 13 & 0 & Nil \\
Paper \& Printing & 1 & 13 & 1 & 7.69 \\
Pharmaceuticals \& Chemicals & 8 & 104 & 8 & 7.69 \\
Services \& Real Estate & 2 & 26 & 3 & 11.54 \\
Tannery & 2 & 26 & 0 & Nil \\
Telecommunication & 1 & 13 & 0 & Nil \\
Textile & 11 & 143 & 6 & 4.20 \\
Travel \& Leisure & 1 & 13 & 1 & 7.69 \\
Total & 88 & 1144 & 194 & 16.96 \\
\hline
\end{tabular}

Table 5 shows, banking industry reports highest disclosures on climate change and global warming and the level of disclosures is $60 \%$. This is due to mandatory green banking policy guidelines of Bangladesh Bank (2011). The guidelines cover the mandatory requirements of disclosure \& reporting of green banking activities e.g. incorporation of Environment and Climate Change Risk in credit risk management (CRM), in-house environment management, green finance, green marketing and creation of climate risk fund etc. In 2013, Bangladesh Bank issued similar mandatory policy guidelines for financial institutions (FIs). So, FIs have started to disclose the climate change and global warming issues in corporate annual reports.

Cement industry also pays attention on climate change through medium level of disclosures. All the companies of cement industry disclosed their concern about tree plantation to reduce the effect of climate change. Premier Cement Ltd mentioned "To maintain ecological balance and to protect our environment our company continuously arranging numerous plantation drives and awareness programs to create environmental consciousness amongst the local inhabitants with the help of its stakeholders; intended to offset carbon emissions associated with the industry revolution in the country. During the period under review the Company planted thousands of saplings in more than 16 different districts in the country 
namely Bogra, Mongla, Rangamati, Bandarban and Cox's Bazar etc." (Premier Cement Ltd, 2015, p. 40)

Industries namely financial institutions, food \& allied and fuel \& power reported few climate change related issues in their annual reports. Their levels of disclosures are $22.12 \%, 20.51 \%$ and $27.69 \%$ respectively. Some other industries reported only one or two issues in their annual reports. They may report those one or two issues to comply industry specific requirements which are mandatory. It is noted that IT, Jute, Tannery and Telecommunication sectors did not disclose any issue related to climate change and global warming in their annual reports.

Table 6. Extent of climate change disclosures

\begin{tabular}{lcc}
\hline No. of sentences & No. of companies disclosing & Percentage $(\%)$ \\
\hline Equal or below 5 sentences & 24 & 47.06 \\
6 to 10 sentences & 10 & 19.61 \\
11 to 15 sentences & 8 & 15.69 \\
16 to 20 sentences & 1 & 1.96 \\
21 to 25 sentences & 3 & 5.88 \\
More than 25 sentences & 5 & 9.80 \\
Total & 51 & 100 \\
\hline
\end{tabular}

Table 6 indicates the volume of climate change disclosures by the number of sentences about the different issues of climate change disclosures noted down by the disclosing companies in their annual reports. Almost half (47.06\%) of the disclosing companies mentioned at best 5 sentences regarding different categories of climate change disclosures in their annual reports. $19.61 \%$ of the disclosing companies reported 6 to 10 sentences. Climate change disclosure practices of $23.53 \%$ of the disclosing companies are considered mediocre because of reporting 11 to 25 sentences. Finally, around $9.80 \%$ of the disclosing companies reported different issues of climate change rigorously as they reported more than 25 sentences.

\section{Conclusions}

Despite less contribution to the global climate change, the companies of Bangladesh are attempting to demonstrate their concerns for the legitimacy of their operations and their social contract with the society through climate change disclosure practices, even in the absence of any mandatory regulation. But the present climate change disclosure practices of the Bangladeshi companies experience the deficiency of more detailed and in-depth practices. With the increasing awareness among the stakeholders regarding the adverse effects of the climate change, it is anticipated that there will be an increasing tendency to provide climate change disclosure practices. Comparative studies will be needed in future to gauge any uprising trend in the climate change reporting practices by the Bangladeshi companies. 


\section{References}

ACCA. (2007). Disclosures on Climate Change: Australia. Association of Chartered Certified Accountants.

ACCA. (2009). Carbon Accounting: Too little too late? London: Association of Chartered Certified Accountants (ACCA).

Ahmad, N. N., \& Hossain, D. M. (2015). Climate Change and Global Warming Discourses and Disclosures in the Corporate Annual Reports: A Study on the Malaysian Companies. Global Conference on Business \& Social Science. Kuala Lumpur: Elsevier Ltd. https://doi.org/10.1016/j.sbspro.2015.01.361

Bangladesh Bank. (2011, Februay 27). Policy Guidelines for Green Banking. Dhaka, Bangladesh: Banking Regulation \& Policy Department.

Bangladesh Bank. (2013, August 11). Policy Guidelines for Green Banking. Dhaka, Bangladesh: Green Banking \& CSR Department.

Belal, A. R., Kabir, M. R., Cooper, S., Dey, P., Khan, N. A., Rahman, T., et al. (2010). Corporate Environmental and Climate Disclosures: Empirical Evidence from Bangladesh. Research in Accounting in Emerging Economies, 10, 145-167. https://doi.org/10.1108/S1479-3563(2010)0000010011

Brac Bank Ltd . (2015). Annual Report 2014.

British American Tobacco Bangladesh Company Limited. (2015). Annual Report 2014.

CECP. (2010). Shaping the future: Solving Socail Problems through Business Strategy. CECP.

Dacca Dyeing and Manufacturing Co. Ltd. (2015). Annual Report 2014.

Deegan, C. (2009). Financial Accounting Theory (3rd ed.). Australia: McGraw-Hill Australia Pty Ltd.

Department of Environment (DoE). (2007). Climate Change and Bangladesh. Climate Change Cell, Government of the People's Republic of Bangladesh, Dhaka.

Donaldson, T. (1982). Corporations and Morality. New Jersey: Prenctice Hall.

Freedman, M., \& Jaggi, B. (2010). Global warming and corporate disclosures: A comparative analysis of companies from the European Union, Japan and Canada. Advances in Environmental Accounting and Management, 4, 129-160. https://doi.org/10.1108/S1479-3598(2010)0000004009

Guthrie, J., \& Abeysekera, I. (2006). Content analysis of social, environmental reporting: what is new?. Journal of Human Resource Costing \& Accounting, 10(2), 114-126. https://doi.org/10.1108/14013380610703120 


\section{Macrothink}

Asian Journal of Finance \& Accounting

ISSN 1946-052X

2017, Vol. 9, No. 2

Hopwood, A. G. (2009). Accounting and the environment. Accounting, Organizations and Society, 34(3-4), 433-439. https://doi.org/10.1016/j.aos.2009.03.002

Intergovernmental Panel on Climate Change . (2007). Climate Change 2007: The Physical Science Basis . Cambridge: Cambridge University Press.

International Federation of Red Cross and Red Crescent Societies. (2014). Bangladesh: Flood . International Federation of Red Cross and Red Crescent Societies.

Kreft, S., Eckstein, D., Dorsch, L., \& Fischer, L. (2016). Global Climate Risk Index 2016. Berlin: Germanwatch e.V.

Luo, I., \& Tang, Q. (2014). Does voluntary carbon disclosure reflect underlying carbon performance? Journal of Contemporary Accounting \& Economics, 10, 191-205. https://doi.org/10.1016/j.jcae.2014.08.003

Luo, L., Tang, Q., \& Lan, Y. (2013). Comparison of propensity of carbon disclosure between developing and developed countries: A resource constraint perspective. Accounting Research Journal, 26(1), 6-34. https://doi.org/10.1108/ARJ-04-2012-0024

Marston, C., \& Shrives P. (1991). The Use of Disclosure Indices in Accounting Research: A Review Article. The British Accounting Review, 23(3), 195-210. https://doi.org/10.1016/0890-8389(91)90080-L

Meng, X. H., Zeng, S. X., Shib, J. J., Qi, G. Y., \& Zhang, Z. B. (2014). The relationship between corporate environmental performance and environmental disclosure: An empirical study in China. Journal of Environmental Management, 145, 357-367. https://doi.org/10.1016/j.jenvman.2014.07.009

Ministry of Environment and Forests (MoEF). (2009). Bangladesh Climate Change Strategy and Action Plan. Dhaka, Bangladesh: MoEF, Government of the People's Republic of Bangladesh.

Ministry of Planning. (2016). Bangladesh Disaster Related Statistics 2015. Dhaka: Bangladesh Bureau of Statistics.

National Polymer Industries Ltd. (2015). Annual Report 2014.

Nurunnabi, M. (2015). Who cares about climate change reporting in developing countries? The market response to, and corporate accountability for, climate change in Bangladesh. 157-186.

Patten, D. M. (2002). The relation between environmental performance and environmental disclosure: a research note. Accounting, Organizations and Society, 27(8), 763-773. https://doi.org/10.1016/S0361-3682(02)00028-4

Pellegrino, C., \& Lodhia, S. (2012). Climate change accounting and Australian mining industry: exploring the links between corporate disclosure and the generation of legitimacy. Journal of Cleaner Production, 36, 68-82. https://doi.org/10.1016/j.jclepro.2012.02.022 
Premier Cement Ltd. (2015). Annual Report 2014.

Rankin, M., Windsor, C. \& Wahyuni, D. (2011). An investigation of voluntary corporate greenhouse gas emission reporting in a market governance system: Australian evidence. Accounting, Auditing \& Accountability Journal, 24(8), 1037-1070. https://doi.org/10.1108/09513571111184751

Solomon, S., Qin, D., Manning, M., Chen, Z., Marquis, M., Averyt, K., . . . Miller, H. 2007). Contribution of Working Group I to the Fourth Assessment Report of the Intergovernmental Panel on Climate Change. Cambridge: Cambridge University Press.

Stechemesser, K., \& Guenther, E. (2012). Carbon accounting: a systematic literature review. Journal of Cleaner Production, 36, 17-38. https://doi.org/10.1016/j.jclepro.2012.02.021

Summit Power Ltd. (2015). Annual Report 2014.

The Daily Star. (2013, November). The Daily Star Archive. Retrieved December 2015, from The Daily Star Web site: http://archive.thedailystar.net/newDesign/cache/cached-news-details-157626.html

United Nations. (1992). United Nations Framework Convention on Climate Change.

World Bank. (2014). Bangladesh: Community-Driven Attempts to Build Climate Change Resiliency. [online] Available at: http://www.worldbank.org/en/news /feature/2014/07/17 /bangladesh-community-driven-attempts-to-build-climate-change-resiliency [Accessed 10 Jun. 2016]

World Bank. (2015a). Salinity Intrusion in a Changing Climate Scenario will Hit Coastal Bangladesh Hard. [online] Available at: http://www.worldbank.org/en/news/feature/ 2015/02/17/salinity-intrusion-in-changing-climate-scenario-will-hit-coastal-bangladesh-hard [Accessed 12 Jun. 2016]

World Bank. (2015b). Retrieved from World Bank: http://www.worldbank.org/en/news/press release/2015/07/01/new-world-bank-update-shows-bangladesh-kenya-myanmar-and-tajikista n-as-middle-income-while-south-sudan-falls-back-to-low-income [Accessed 12 Jun. 2016] 